\title{
ACCOUNTING CURRICULUM AND DATA ANALYTICS
}

Sewon O, Texas Southern University, U.S.A.

Kun Wang, Texas Southern University, U.S.A.

dx.doi.org/10.18374/RBR-19-2.3

\begin{abstract}
This study describes what data analytics is in a business and accounting context and examines how and why data analytics should be incorporated in the accounting curriculum. The study looks at the two approaches: stand-alone data analytics courses/curriculum and incorporation of data analytics in existing accounting courses. It compares the data analytics programs by different universities in a metropolitan area in the State of Texas. The study also suggests a development of a comprehensive accounting analytics course.
\end{abstract}

Keywords: Data Analytics, Accounting Analytics, Accounting Curriculum 